\title{
A Sala de Aula Invertida como possibilidade no combate à evasão escolar
}

\section{The Inverted Classroom as a possibility in the fight against school dropout}

\section{El Aula Invertida como posibilidad en el combate a la evasión} escolar

Debora da Costa Pereira ${ }^{1}$ Fábio André Hahn² Marcos Clair Bovo ${ }^{3}$

${ }^{1}$ Especialista em Educação Especial pelo Instituto de Estudos Avançados e PósGraduação (ESAP). Especialista em Gestão Pública pela Faculdade São Braz. Graduada em Letras - Português/Inglês pelas Faculdades Integradas do Vale do Ivaí (UNIVALE). Chefe da Seção Pedagógica e de Assuntos Estudantis no Campus

Ivaiporã do Instituto Federal do Paraná (IFPR). Atua como pesquisadora no Núcleo de Estudos em Formação Docente. E-mail: debora.pereira@ifpr.edu.br, Orcid: https://orcid.org/0000-0002-7033-3105

${ }^{2}$ Pós-doutor pela Universidade Estadual do Centro-Oeste (UNICENTRO). Doutor e mestre em História pela Universidade Federal Fluminense (UFF). Licenciado em

História pela Universidade Estadual do Oeste do Paraná (UNIOESTE). Professor da Universidade Estadual do Paraná (UNESPAR). Editor da Revista TEL - Tempo, Espaço e Linguagem da Unicentro. Coordenador do mestrado em História Pública.

E-mail: fabioandreh@gmail.com, Orcid: http://orcid.org/0000-0001-6148-5900

${ }^{3}$ Doutor em Geografia pela Universidade Estadual Paulista Júlio de Mesquita Filho (UNESP), Campus de Presidente Prudente, SP. Mestre em Geografia pela Universidade Estadual de Maringá (UEM). Especialista em Metodologia de Ensino pelas Faculdades Integradas Norte do Paraná (UNOPAR). Graduado em Geografia pela UEM. Professor adjunto da Universidade Estadual do Paraná (UNESPAR). E-mail: mcbovo69@gmail.com, Orcid: https://orcid.org/0000-0003-3582-6702 
Resumo: A evasão escolar é um desafio a ser superado pelas instituições de ensino no Brasil. Com índices cada vez mais preocupantes e causas variadas, a evasão escolar é um fator que interrompe a formação dos jovens brasileiros. Entre as principais causas do abandono da escola pelos discentes, destaca-se a falta de interesse pelos estudos. Partindo dessa questão, o presente artigo objetiva tratar do modelo de Sala de Aula Invertida, assumindo esse modelo como parte da aprendizagem ativa enquanto alternativa e possibilidade no combate à evasão escolar. Com base em pesquisa de campo com docentes e com discentes do Instituto Federal do Paraná, Campus Ivaiporã, e análise bibliográfica, os resultados da investigação permitiram verificar a eficiência do método e a otimização do tempo das aulas, gerando melhores condições de aprendizagem.

Palavras-chave: Sala de Aula Invertida; evasão escolar; educação básica.

\begin{abstract}
School dropout is a challenge to be overcome by educational institutions in Brazil. With increasingly worrying rates and varied causes, school dropout is a factor that interrupts the training of Brazilian youth. Among the main causes of dropping out of school, there is a lack of interest in studies. Based on this question, this article aims to deal with the Inverted Classroom model, assuming this model as part of active learning as an alternative and possibility in the fight against school dropout. Based on field research with teachers and students of the Federal Institute of Paraná, Campus Ivaiporã, and bibliographic analysis, the results of the research allowed to verify the efficiency of the method and the optimization of class time, generating better learning conditions.
\end{abstract}

Keywords: Inverted Classroom; school evasion; basic education.

Resumen: La evasión escolar es un desafío a ser superado por las instituciones de enseñanza en Brasil. Con índices cada vez más preocupantes y causas variadas, la evasión escolar es un factor que interrumpe la formación de los jóvenes brasileños. Entre las principales causas del abandono de la escuela por los discentes, se destaca la falta de interés por los estudios. A partir de esta cuestión, el presente artículo objetiva tratar el modelo de Sala de Aula Invertida, asumiendo ese modelo como parte del aprendizaje activo como alternativa y posibilidad en el combate a la evasión escolar. Con base en investigación de campo con docentes y con discentes del Instituto Federal de Paraná, Campus Ivaiporã, y análisis bibliográfico, los resultados de la investigación permitieron verificar la eficiencia del método y la optimización del tiempo de las clases, generando mejores condiciones de aprendizaje.

Palabras clave: Sala de Clase Invertida; evasión escolar; educación básica. 


\section{INTRODUÇÃO}

É cada vez mais frequente surgir informações que revelam os problemas e os desafios enfrentados pelas instituições de ensino no Brasil, desde más condições de infraestrutura até falta de adequadas políticas públicas e, em decorrência desses fatores, a evasão escolar, que tem crescido a cada ano. Dados do Instituto Nacional de Estudos e Pesquisas Educacionais Anísio Teixeira (INEP) mostram que, de acordo com o Censo Escolar, entre os anos de 2014 e 2015, se forem consideradas todas as séries do Ensino Médio no Brasil nesse período, a evasão escolar chegou a 11,2\% do total de discentes nesse nível de ensino.

Os altos índices de evasão impactam financeira e pedagogicamente, revelando a falta de adequadas políticas públicas para o setor e resultando em prejuízos sociais em curto e longo prazo. Há, sim, impactos financeiros, pois o investimento anual mínimo em nível nacional por aluno é de $\mathrm{R} \$$ 3.016,67 (três mil, dezesseis reais e sessenta e sete centavos), isso de acordo com a Portaria Interministerial n. 10, de 28 de dezembro de 2017, publicada no Diário Oficial da União (BRASIL, 2017). Além disso, existem as bolsas e os auxílios estudantis, que são mais outros recursos cedidos pelo governo federal e pelas instituições de fomento para os vários níveis de ensino. E há, sim, também impactos pedagógicos, pois não se obtém qualificação formativa quando se gera redução de oportunidades.

Diante desse cenário de evasão escolar crescente, o presente artigo propõe, de forma exploratória, apresentar uma possibilidade para um dos principais motivos da evasão escolar: a falta de interesse dos discentes.

$\mathrm{O}$ atual modelo das instituições de ensino já não desempenha a função social de outrora e essa constatação é consenso entre pesquisadores da área. A proposta aqui, portanto, é tratar apenas de uma das variáveis, ou seja, as metodologias de ensino empregadas nas aulas, a partir de um estudo de caso com discentes e docentes do Instituto Federal do Paraná (IFPR), Campus Ivaiporã. 


\section{EVASÃO ESCOLAR}

O início da evasão escolar é marcado, na maioria das vezes, por faltas esporádicas dos discentes, conforme estudo publicado no InfoGeekie em 2015. Depois, vão ocorrendo ausências mais frequentes até o completo afastamento do discente da escola. Considera-se, portanto, ser discente evadido aquele que para de frequentar a escola antes do término do ano letivo, não se matriculando em outra instituição para concluir a série/ano que está cursando. Conforme Cristiane Cabral Johann (2012, p. 65),

A evasão é um fenômeno caracterizado pelo abandono do curso, rompendo com o vínculo jurídico estabelecido, não renovando o compromisso ou sua manifestação de continuar no estabelecimento de ensino. Esta situação de evasão é vista como abandono, sem intenção de voltar, uma vez que não renovando a matrícula rompe-se o vínculo existente entre aluno e escola.

Para combater a evasão escolar, é necessário conhecer as suas causas e as suas consequências. Entre inúmeras causas justificadas para a evasão, a maior parte não cabe à escola, pois se trata de questões pessoais e sociais, questões relacionadas a emprego, à saúde, à família, entre outros fatores. Por outro lado, existem ações que são da responsabilidade das escolas, como é o caso da falta de motivação dos discentes, o que não é algo novo no cenário educacional. De acordo com estudo divulgado pela Fundação Getúlio Vargas em 2009, sob coordenação de Marcelo Côrtes Neri , 40,3\% dos jovens de 15 a 17 anos tinham abandonado os estudos por "falta intrínseca de interesse" (NERI, 2009, p. 5). Isso reforça a ideia de que são necessárias mudanças urgentes nos rumos das escolas, pois o atual modelo recebe críticas como: falta de foco, excesso de conteúdo e descontextualização com a realidade dos discentes.

Centrada em um modelo de ensino verbalista e memorístico, já combatido há décadas no campo teórico, essa metodologia apresenta sobrevida na realidade do ensino nas escolas. Nesse mesmo caminho, Maria Lúcia Setúbal apresenta alguns exemplos de situações nas quais a própria escola é protagonista como causa da evasão escolar:

[...] criação de obstáculos ao acolhimento de alunos que retornam

à escola, geralmente oriundos de famílias de alta vulnerabilidade; 
distância entre o currículo formal e a realidade do mundo desses discentes; desvalorização da história e das vivências desses alunos e de suas famílias; culpabilização da família pelo malogro escolar dos filhos; dificuldade da escola em aceitar e lidar com a diversidade, a diferença e o preconceito. Essas atitudes, embora de difícil medição, são muitas vezes determinantes nos baixos resultados de aprendizagem e na evasão e abandono da escola (SETÚBAL, 2010, p. 357).

Apesar de enfocarmos no desinteresse por parte dos discentes com maior densidade, está correta Setúbal ao afirmar que as causas da evasão escolar são variadas, atreladas de modo geral aos fatores socioeconômicos, culturais, geográficos e pedagógicos. Segundo dados do Instituto Brasileiro de Geografia e Estatística (IBGE, 2017), por meio da PNAD Contínua, em 2016 mais da metade da população adulta brasileira tinha concluído apenas o Ensino Fundamental. Entre as causas apresentadas para a evasão, dois fatores foram destacados com maior ênfase: necessidade de assumir trabalho e falta de interesse.

De acordo com a PNAD Contínua 2016,

O efeito do atraso escolar também pode ser observado entre os jovens de 15 a 17 anos de idade que estavam fora da escola. No Brasil, em 2015, 15,0\% dos jovens dessa faixa etária não estudavam, totalizando cerca de 1,6 milhão de jovens. Entre os jovens que haviam evadido a escola precocemente sem terminar o ensino médio (1,3 milhão de jovens), 61,4\% abandonaram a escola sem concluir o ensino fundamental, $22,1 \%$ concluíram o ensino fundamental e $16,4 \%$ tinham ensino médio incompleto. Isso significa que a maioria desses jovens sequer estava apta a ingressar no ensino médio (61,4\%), evidenciando que parte significativa da evasão escolar dessa faixa etária ocorre em etapas que antecedem esse nível.

Seguindo esse contexto, utilizar métodos de ensino que tornem a aprendizagem ativa aos discentes, despertando-Ihes interesse e motivação, pode ser uma alternativa benéfica no processo formativo, aumentando a participação e diminuindo os casos de evasão por falta de interesse.

\section{SALA DE AULA INVERTIDA COMO POSSIBILIDADE}

Cada discente tem seu tempo e modo de assimilar os conteúdos e de construir o saber, o que reforça o fato de que o aprendizado não é ho- 
mogêneo. Se é assim com o aprendizado, não poderia ser diferente com a forma de ensinar, pois, conforme destaca Iraci Cunha Ferreira Costa (2013), nem todos aprendem ao mesmo passo, portanto "[...] é importante analisar cada discente para diagnosticar o seu nível de aprendizagem para que se saiba o que ele precisa aprender e de que forma essa aprendizagem deve acontecer".

Levando em consideração a heterogeneidade e a tecnologia disponível para o uso no processo formativo, as salas de aula com carteiras enfileiradas e o modelo de aprendizagem passiva - "bancária", segundo Freire (1987, p. 33) -, baseado na transmissão de conhecimento pelos docentes, estão obsoletos e desinteressantes aos discentes. É preciso, portanto, que esse modelo de aprendizagem de passividade seja alterado com a contribuição de novos referenciais, de novos métodos de ensino que possibilitem colaborar para transformar o discente passivo em ativo, em um cidadão apto a viver em sociedade e agir nela, com autonomia e criticidade, "como sujeitos" (FREIRE, 1987, p. 34).

Nesse sentido, a chamada Sala de Aula Invertida se apresenta como uma possibilidade de mudança. Esta prática de ensino faz parte do blended learning ${ }^{1}$, método americano aplicado inicialmente em cursos superiores, o qual, no Brasil, é conhecido como ensino híbrido. Testado em algumas situações, esse tipo de ensino tem demonstrado bons resultados (LEDESMA, 2011; RODRIGUES JUNIOR; CAMARGO, 2016), valorizando a interação e a colaboração, que são princípios de caracterização de maior interdisciplinaridade.

A inverted classroom, conhecida no Brasil como Sala de Aula Invertida, teria sido usada inicialmente em uma disciplina de Microeconomia, em 1996, na Miami University, de Ohio/EUA, conforme Valente (2014, p. 86). De acordo com o autor, o método foi implantado pelos autores após se constatar que a metodologia tradicional não contemplava a aprendizagem de todos os discentes. Trata-se, portanto, de um método simples e que consiste em, como o próprio nome já diz, inverter a ordem do processo.

\footnotetext{
${ }^{1}$ A Sala de Aula Invertida é uma das subcategorias do ensino híbrido, junto a rotações por estações, laboratório rotacional e rotação individual.
} 
Segundo Valente (2014, p. 85), a Sala de Aula Invertida é uma modalidade que ganhou maior impulso a partir do sucesso de outra modalidade, já há mais tempo conhecida como e-learning. A contribuição está na possibilidade de haver o estudo do conteúdo e das instruções via internet/on-line antes da programação realizada em sala de aula. Havendo essa atividade antes da sessão em sala de aula, faz-se possível que, presencialmente, ocorra a resolução de problemas, realização de projetos e discussões em grupo 2 .

A proposta da Sala de Aula Invertida é fazer com que o discente tenha uma maior aproximação com o conteúdo antes das aulas e das explicações dos docentes, recebendo desse profissional encaminhamentos sobre o que deve ser estudado a partir de diferentes suportes, como é o caso da utilização de vídeos, de áudios, de pesquisas na internet, entre outros. A proposta, portanto, é que o discente chegue à escola com informações preliminares sobre determinado conteúdo, viabilizando uma prática interativa e colaborativa na sala de aula. Por esse motivo, Schneider et al. (2013, p. 71) definem a Sala de Aula Invertida como uma possibilidade de organização curricular diferente, em que se "[...] permita ao aluno o papel de sujeito de sua própria aprendizagem, reconhecendo a importância do domínio dos conteúdos para a compreensão ampliada do real e mantendo o papel do professor como mediador entre o conhecimento elaborado e o aluno".

A qualidade desse processo vai depender do tempo e do direcionamento do docente no preparo das aulas, na escolha e na indicação dos materiais a serem estudados, uma vez que é ele quem vai extrair as informações iniciais e repassá-las aos discentes. Se essa etapa inicial for bem elaborada, os resultados terão maiores chances de serem satisfatórios e superar o modelo de ensino verbalista, mais comum nas escolas hoje em dia.

Segundo Valente (2014, p. 92-3), quando o processo da Sala de Aula Invertida é bem direcionado, podem ser destacados pontos positivos, como o contato prévio com o conteúdo por meio das atividades on-line e o incentivo aos discentes a se prepararem para as aulas, propiciando a cada um a

\footnotetext{
${ }^{2}$ A diferença entre blended learning e e-learning está no fato de que o primeiro é um derivado do segundo, mas com característica mista, em que os encontros presenciais não são individualizados.
} 
autonomia de estudar no seu ritmo, buscando o seu melhor desempenho. Esses fatores favorecem a otimização do tempo da aula, pois, devido ao fato de a explanação do conteúdo já ter sido disponibilizada aos discentes anteriormente, o docente pode dedicar mais tempo da aula no aprofundamento das discussões e das análises acerca do conhecimento adquirido.

Com relação às críticas feitas ao método, Valente (2014, p. 93-4) evidencia algumas identificadas por Hennick (2014) e por lan Bogost (2013), a começar pelo fato de alguns docentes defenderem que, se já é difícil os discentes assimilarem os conteúdos expostos no modelo tradicional, será ainda mais difícil por meio de atividades on-line. Outros docentes acreditam que o método é muito dependente de tecnologias, o que poderia tornar a aprendizagem desigual dentro das possibilidades de cada ambiente. Há também os docentes que salientam que preparar vídeos a serem assistidos pelos discentes previamente às aulas seria restringir os conteúdos que poderiam ser trabalhados de maneira mais detalhada por meio de combinações de leituras de livros didáticos. Além das questões pedagógicas, o barateamento do processo educacional, nesse caso, também é algo citado nas críticas dos referidos autores.

É certo que, por se tratar de algo novo, o sucesso do método depende de aperfeiçoamentos e de testes a serem realizados em diferentes realidades. O formato não necessariamente é dependente de atividades exclusivamente digitais, e essa é uma das etapas com as quais ainda é preciso avançar. O espaço da sala de aula não perde o seu valor, mas, pelo contrário, é valorizado na sua essência.

O modelo de Sala de Aula Invertida já vem sendo utilizado em várias instituições de ensino brasileiras ${ }^{3}$, de nível médio e de nível superior, como meio na busca pela qualidade da aprendizagem, aumentando a participação e o interesse dos discentes. Mike Fritz (2013), em seu estudo intitulado "How one school turned homework on its head with 'flipped' instruction" ("Como uma escola inovou a lição de casa com instruções 'invertidas'”), aborda essa temática com base em pesquisa realizada na Clintondale High School, ao

\footnotetext{
${ }^{3}$ Esse método tem sido usado por docentes da USP, da PUC/SP, da Presbiteriana Mackenzie, do Instituto Federal de Educação, Ciência e Tecnologia do Paraná, da Unicesumar - Maringá e de outras universidades.
} 
norte de Detroit. De acordo com o autor, em 2010 foi adotada na referida escola um método de abordagem invertida e, a partir de então, as taxas de reprovação caíram em mais de 50\%. Segundo Fritz, os proponentes do uso da metodologia argumentam que deixar as aulas gravadas elimina dos docentes a monotonia de ministrar aulas com o mesmo conteúdo repetidas vezes, sendo que os discentes podem retroceder ao conteúdo quantas vezes julgarem necessárias.

O Gennera Blog publicou, em 2017, um estudo sobre os benefícios da Sala de Aula Invertida. Nesse estudo, a autonomia discente, a construção mútua do conhecimento, a integração entre discentes e docentes e a otimização das aulas foram destacados como pontos positivos na aplicação do método. O estudo demonstra ainda que houve diminuição da evasão escolar e aumento da participação dos discentes, após docentes de Física introduzirem esse método na Universidade da Columbia Britânica.

Estudos como esses demonstram o quanto esse método simples pode ser, ao mesmo tempo, inovador e eficiente. Ao contrário da metodologia verbalista - método que ainda vigora em várias instituições de ensino no Brasil e em que o aluno é receptor, apenas -, aulas invertidas são aliadas que podem tornar as aulas mais eficientes e inclusivas. Marcos de Aguiar Villas-Bôas (2017, p. 2), acerca das aulas invertidas, salienta que:

Em lugar de alunos cansados, desmotivados muitas vezes por não conhecerem nada sobre o assunto e julgarem-no enfadonho à primeira vista, observa-se que, na "aula invertida", eles se sentem mais seguros, motivados por terem em suas mãos as rédeas do processo de construção do conhecimento, por já saberem um pouco do tema e terem se aprofundado naquilo que mais Ihes interessou.

Nesse sentido, o processo avaliativo na aprendizagem ativa passa a ter mais êxito, pois, quando os discentes assimilam os conteúdos de fato, as avaliações passam de respostas decoradas a respostas elaboradas, ou ainda o processo não precisa se restringir somente a avaliações bimestrais, mas sim a uma avaliação contínua, baseada em atividades abertas, tais como seminários, pesquisas expositivas, entre outros.

Assim, portanto, para que a proposta da Sala de Aula Invertida possa ser avaliada com maior precisão, optamos, neste momento, por apresentar 
um estudo de caso que revela os primeiros resultados com a avaliação dessa metodologia de ensino no contexto do IFPR.

\section{A SALA DE AULA INVERTIDA: O CASO DO INSTITUTO FEDERAL DO PARANÁ}

O locus para a aplicação desta pesquisa é o IFPR, Campus Ivaiporã. Trata-se de uma instituição de ensino da rede pública federal, localizada na mesorregião Norte Central Paranaense, que iniciou as suas atividades pedagógicas em 2010, ofertando cursos técnicos na modalidade subsequente e expandindo gradativamente a sua estrutura física, bem como a oferta de cursos. Atualmente, o Campus atende discentes de aproximadamente dez municípios, oferecendo cursos técnicos nas modalidades integrado ${ }^{4}$ e subsequente ${ }^{5}$, bem como cursos de nível superior ${ }^{6}$.

A pesquisa foi realizada em junho de 2018 e consistiu na aplicação de questionários junto a docentes e a discentes envolvidos com o método de Sala de Aula Invertida que se disponibilizaram a participar da pesquisa, a saber: dois docentes da área de Ciências Humanas que passaram a utilizar o método no início do ano letivo corrente, portanto com resultados e experiência ainda em fase de experimentação, avaliação e redirecionamentos.

Quanto aos discentes, participaram da pesquisa 191 de um total de 274, na faixa etária entre 14 e 19 anos, dos cursos Técnicos em Informática, Eletrotécnica e Agroecologia - todos eles integrados ao Ensino Médio. O método é aplicado junto aos discentes dos quatro anos do curso Técnico em Informática e do curso em Eletrotécnica, bem como do terceiro e quarto ano do curso Técnico em Agroecologia.

Os questionários aplicados continham quatro questões discursivas dirigidas aos docentes e questões objetivas dirigidas aos discentes. Além

\footnotetext{
${ }^{4}$ Cursos oferecidos nas áreas de Informática, Agroecologia e Eletrotécnica, com duração de quatro anos, nos quais se integram as disciplinas do núcleo comum às disciplinas técnicas de cada área, formando egressos com certificação de Ensino Médio Técnico.

${ }^{5}$ Curso oferecido na área de Eletrotécnica, com duração de dois anos, para discentes que já concluíram o Ensino Médio e desejam fazer um curso puramente técnico.

${ }^{6}$ Tecnologia em Agroecologia, com duração de três anos, e Licenciatura em Física, com duração de quatro anos.
} 
das questões, o questionário aos discentes foi elaborado constando também de um espaço aberto, destinado a avaliar o que os discentes consideram importante mencionar acerca do método, não se restringindo a respostas objetivas.

\subsection{Percepção dos docentes}

Ao serem questionados sobre o principal fator que teria levado à implantação do método da Sala de Aula Invertida, isso depois das diferentes experiências no ensino, o Docente $A$ ressaltou o fator motivacional, como já constatado em outros momentos. A percepção sempre é a de que os discentes não se sentem ativos dentro do processo formativo, sendo necessário tornar o ambiente escolar mais interessante, viabilizando situações em que eles se tornem "sujeitos" do processo, conforme já destacava Freire (1987, p. 34). Segundo o Docente A,

No ano de 2017 tive a oportunidade de ter uma conversa franca com os discentes. Sentamos em círculo e perguntei para eles o que sentiam com relação à escola - não necessariamente a atual. De pronto, eles disseram que a escola é desinteressante, que é muito chato vir e ficar sentado o tempo todo, aprendendo coisas que eles não estão a fim. Muitos disseram que eles, às vezes, aprendiam mais pesquisando na internet antes da prova do que durante o ano todo. A partir destas conversas, comecei a pesquisar alguma metodologia que alterasse a lógica da sala de aula. Foi aí que me deparei com a sala de aula invertida (Docente A).

Quanto ao Docente B, a motivação dele partiu de questões pedagógicas, como proporcionar aos discentes que trabalham - ou que, por algum outro motivo, não conseguem assistir à aula toda - a possibilidade de avaliá-la e acessá-la a qualquer momento. As melhorias na execução dos trabalhos e das atividades são importantes, conforme enfatiza o Docente B:

[...] tarefas e trabalhos passaram a ser realizados em sala de aula, com a minha presença como orientador. [...] esse método permite que eu possa verificar, de forma mais individualizada, as dificuldades de cada aluno ou grupo de alunos, visto que nossas turmas possuem mais de 30 alunos por sala.

Quanto à forma de aplicação, os dois docentes utilizaram como recurso o podcast, gravando áudios sobre a temática a ser trabalhada e os disponibilizando aos discentes com uma semana de antecedência. Os discentes 
ouvem e fazem um relatório sobre o conteúdo do áudio para ser entregue no dia da aula, como forma de os docentes acompanharem as reações da turma. Durante a aula, são tiradas as dúvidas referentes ao conteúdo previamente estudado e realizadas atividades práticas e também, por vezes, atividades teóricas, em grupo ou individuais.

Essa forma de aplicação possibilita mesclar, em determinados momentos, segundo os docentes, o ensino híbrido e o ensino tradicional, invertendo os papéis entre docente e discentes, não impedindo que, em outros momentos, se faça uso de aulas expositivas complementares de acordo com a necessidade apresentada. Os docentes fizeram questão de ressaltar que a proposta de Sala de Aula Invertida ainda está em fase de testes e sendo adaptada conforme a realidade dos discentes, portanto muito mais flexível à realidade social.

A segunda indagação feita aos docentes foi quanto à percepção deles, a partir do uso do método da Sala de Aula Invertida, sobre o interesse, a participação e o rendimento dos discentes. Ambos afirmaram uma mudança de perfil dos alunos, destacando que:

No início, todos pareceram bem empolgados com a ideia e isso, realmente, aconteceu nos primeiros meses com quase todas as turmas. Contudo, ao passar o tempo, percebi que algumas turmas deixaram de ouvir os podcasts. A minha hipótese é a de que qualquer coisa que entre na rotina desinteressa e eles já desistem da metodologia. Mesmo assim, o rendimento dos discentes aumentou (Docente A).

Sim, alguns alunos que não produziam tarefas ou trabalhos passaram a realizar as anotações, porém outros alunos não tiveram a mesma postura, mas, com a sequência das aulas, eles têm me procurado para que eu viabilize novos prazos de entrega de anotações anteriores. [...] Outro elemento importante é em relação ao rendimento - alunos com maior dificuldade passaram a me procurar com mais frequência durante a aplicação de atividades em sala de aula. [...] Por conta do método ter sido iniciado apenas no início do segundo bimestre, ainda não foi possível desenvolver muitas atividades, porém a possibilidade de outras atividades em sala de aula tem instigado o interesse em alguns alunos (Docente B).

Destaca-se, na resposta do Docente A, que, ao encontro do que salienta Cíntia Moralles Camillo (2017), não se trata de substituir uma metodologia 
de ensino por outra, mas sim de complementá-las entre si, a fim de tornar o processo formativo interessante e participativo. Já na resposta do Docente B é importante observar que, no início, não foram todos os discentes que tiveram a mesma postura diante da mudança de hábitos de estudos, o que parece ser natural, levando em consideração que toda mudança causa certa insegurança, porém isso tende a mudar para uma postura mais comprometida e participativa entre os discentes e o despertar de interesse quando são propostas outras atividades.

A terceira pergunta que compôs o questionário docente visava saber quais eram as dificuldades encontradas pelos docentes na aplicação do método da Sala de Aula Invertida. Segundo o Docente A:

Como disse, parece que, quando algo entra na rotina, os discentes desistem novamente. Pode ser a metodologia mais inovadora, dinâmica, inédita, se ela se repetir, os discentes deixarão de fazê-la. Para tentar driblar isso, eu estou intercalando aulas nas quais eu resolvo alguns exercícios conjuntamente em sala - no estilo aula tradicional, com aulas nas quais eles resolvem os exercícios sozinhos - ou em grupos. De todo modo, acredito que essas dificuldades também são encontradas na metodologia tradicional, e eu percebi que, com a sala de aula invertida, eu consigo resgatar alguns discentes que se mostravam desinteressados com a metodologia tradicional.

Mais uma vez se destaca a importância da aproximação de estratégias de ensino, considerando a heterogeneidade dos discentes, que vão se adaptando melhor a determinado tipo de metodologia. O importante é que se propicie a aprendizagem de acordo com as possibilidades de cada discente.

Acredito que a maior dificuldade é fazer com que o discente entenda a necessidade de desenvolver sua autonomia nos estudos, tanto em sala de aula quanto em casa; em segundo lugar é o desgaste para o desenvolvimento do método, pois ele exige algumas etapas, que, na sequência, são: preparo da aula, desenvolvimento de roteiro de gravação, gravação de áudio, edição e produção do podcast e, por fim, o planejamento da aula (o que vai se desenvolver e como - trabalho, debate, questionário, aprofundamento de questões etc.). A correção de atividades também é um trabalho desgastante e cansativo, já que em todas aulas são entregues relatórios e a aula precisa ser avaliada de alguma forma - participação coletiva, entrega de trabalhos, discussões, debates etc. (Docente B). 
O Docente B chama a atenção para dois aspectos que dificultam a aplicação do método, um relacionado aos discentes e outro ao trabalho docente. No concernente aos discentes, a dificuldade está relacionada à falta de autonomia dos discentes ao estudar. Quanto ao que diz respeito ao trabalho docente, toda mudança requer sair da zona de conforto e dedicar esforço extra. Isso é algo realmente desgastante, porém, satisfatório.

Por fim, a quarta questão indagada aos professores tratou de apurar sobre o fato de terem verificado motivação maior por parte dos discentes com a utilização do método da Sala de Aula Invertida. O Docente A destacou o seguinte:

Acredito que sim. [...]. Com essa metodologia, o discente que possui muita dificuldade, ou está desmotivado, pode receber uma atenção especial do docente, pois há tempo hábil para isso, coisa que se torna impossivel em uma aula tradicional. Temos um exemplo ótimo para usar: uma aluna está de licença-maternidade e ela não está perdendo nenhuma aula de Sociologia, pois ela pode ouvir as aulas em casa!

A Sala de Aula Invertida possui alguns benefícios que permitem meIhorias, como foi exposto o exemplo da gestante, mas também poderia ser atribuída a outros fatores. Em outras situações, essa discente seria uma forte candidata a abandonar a escola, porém a possibilidade de estudar os conteúdos em casa, sem perder a explicação do docente, faz com que consiga obter êxito em seus estudos. O Docente $B$ reforça destacando o elemento motivador como uma barreira para a evasão escolar, mas não a solução definitiva: "[...] a resposta seria sim, alunos motivados são menos suscetiveis à evasão. Mas não podemos nos esquecer de que o método em si não é a solução para motivar os alunos, depende de como ele é aplicado e sua exaustiva repetição pode fazer com que ele se torne tão enfadonho quanto o método tradicional".

Assim, apesar do pouco tempo de experiência na aplicação da metodologia, os docentes expuseram contribuições significativas de ganhos dos discentes, mas, ao mesmo tempo, elencaram fatores que precisam ser aperfeiçoados e adaptados para cada realidade. A metodologia é apenas um caminho e precisa ser muito bem executada, caso contrário apresentará os mesmos problemas já existentes nos métodos de ensino presentes nas escolas hoje. Conforme os docentes expuseram, a metodologia, enquanto 
motivadora, poderia ser entendida como uma possibilidade de combate à evasão, no entanto, para esse caso em especial, ainda é cedo para concluir definitivamente os impactos gerados.

\subsection{Percepção dos discentes}

Após apresentar a percepção dos docentes com relação ao método da Sala de Aula Invertida, é oportuno expor quais foram as percepções dos discentes em suas respostas ao questionário aplicado. Nesse questionário, as questões, em sua maior parte, foram objetivas, apresentando apenas uma opção para descrição aberta sobre a percepção que tiveram sobre a metodologia. Na questão aberta, apenas 47 discentes se manifestaram, portanto apenas $24,6 \%$ dos participantes, o que não reduziu a importância e a relevância das respostas dadas.

Quando questionados sobre se gostam de estudar seguindo o método da Sala de Aula Invertida, percebeu-se pelas respostas que, por se tratar de algo novo - ainda em fase de adaptação e experimentação -, que exige autonomia, mudança de hábitos de estudo, tanto na escola quanto em casa, a maioria dos discentes apresentou dúvidas, conforme o Gráfico 1. A mudança metodológica se refletiu em uma maior participação, mas também em um rompimento da comodidade das aulas expositivas, teoricamente sob responsabilidade dos docentes, que exigem menor participação e interação, o que não necessariamente representa melhoria na qualidade da aprendizagem.

Gráfico 1 - Você gosta de estudar seguindo o método de Sala de Aula Invertida?

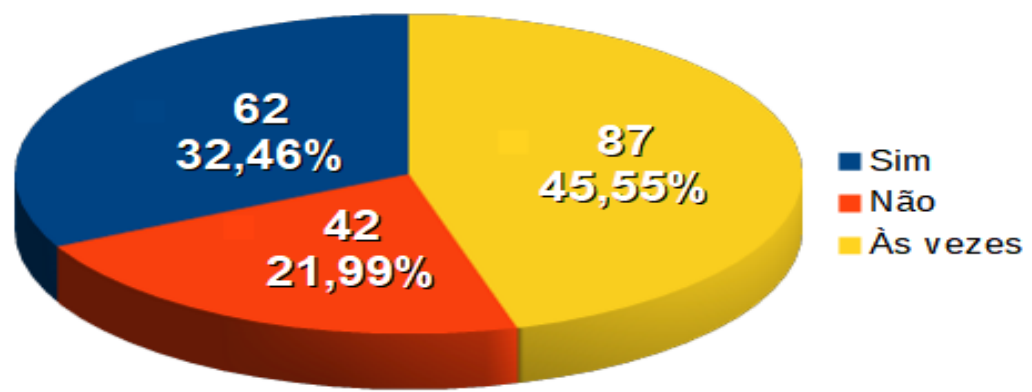

Fonte: Pesquisa realizada pelos autores. 
A dúvida sobre se gostam ou não desse tipo de aula representa a necessidade de acompanhamento e avaliação contínua, não apenas acerca do que gostam mais, mas sobre a melhoria ou não no desempenho quanto à aprendizagem. Dois comentários apresentados pelos discentes chamam a atenção sobre estudar seguindo esse método: um discente de Informática salientou que, "[...] através desse método, principalmente com vídeo-aula e/ou podcast, é possível estudar segundo o ritmo de cada aluno, podendo avançar, voltar e pausar o vídeo ou áudio". Diferentemente, um discente de Agroecologia registrou, contudo, que "[...] o método é bom, porém não são todos que 'ouvem' e decorrente a isto fica 'perdido' na aula". Essas percepções, bem como os dados coletados, apontam pontos positivos no método, mas alertam para a necessidade de constante avaliação e adaptações.

Quando indagados sobre se acreditam no mérito dessa metodologia, discentes e docentes afirmaram a vantagem de terem conseguido debater melhor os conteúdos durante as aulas e os discentes disseram ter tido uma impressão diferente de ensino e aprendizagem. Informaram que a taxa de dúvidas diminuiu e a interação em sala de aula aumentou para a maior parte deles, mesmo que os índices ainda sejam variados, contando com o fato de que essas intervenções ainda são recentes e difíceis de avaliar, especialmente em termos de aprendizagem.

Gráfico 2 - Você acredita que, com o método da Sala de Aula Invertida, discentes e docentes conseguem debater melhor os conteúdos durante as aulas?

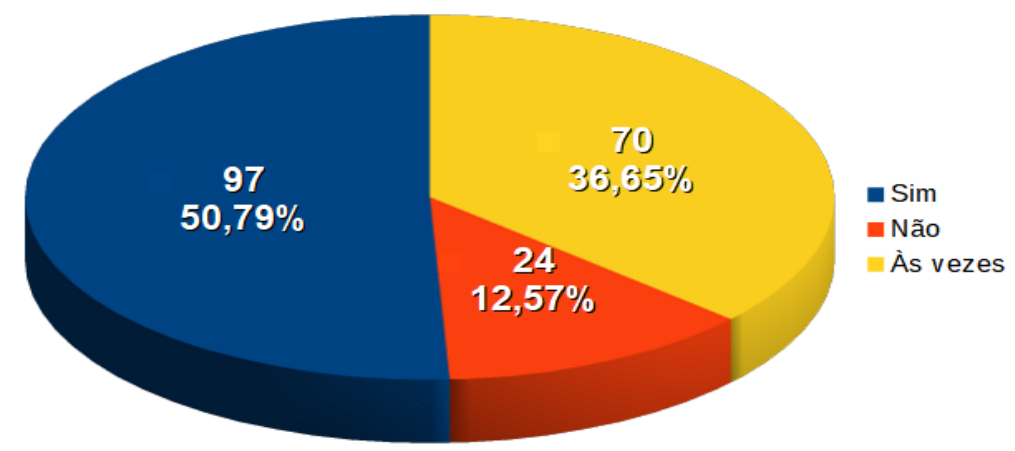

Fonte: Pesquisa realizada pelos autores. 
Os dados coletados corroboram a afirmação de Villas-Bôas (2017) de que um melhor acompanhamento pode propiciar maior interação acerca dos conteúdos. Da mesma forma, quando os discentes foram questionados sobre se ter contato com o conteúdo por meio de uma explicação prévia do docente, antes de esse conteúdo ser trabalhado em sala de aula, os ajudaria na aprendizagem (Gráfico 3), observou-se novamente a predominância positiva dessa iniciativa, apesar dos altos índices de dúvidas dos discentes sobre os resultados gerados.

\section{Gráfico 3 - Ter contato com o conteúdo por meio de uma explicação} prévia do docente ajuda você na aprendizagem?

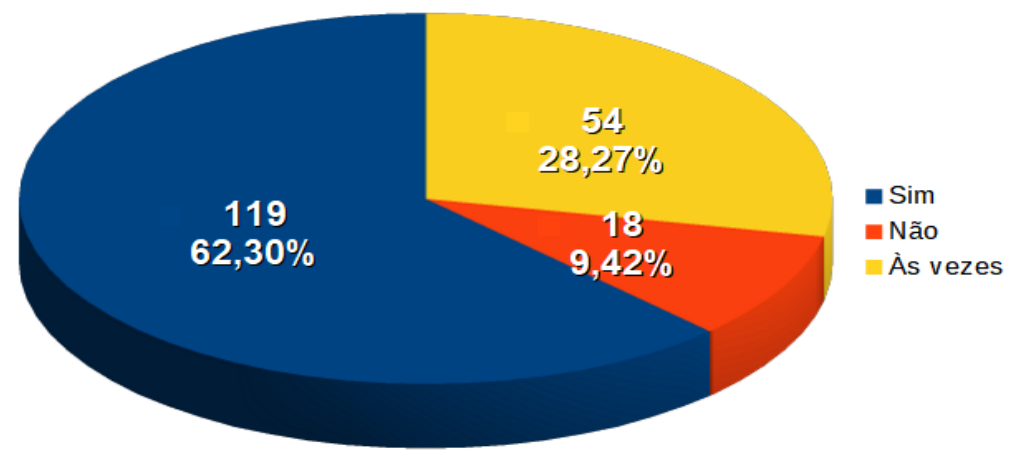

Fonte: Pesquisa realizada pelos autores.

Nesse caso parece mais evidente a melhoria apontada pela metodologia na percepção dos discentes, apesar de a dúvida ainda representar uma taxa alta. Um discente de Eletrotécnica salientou que "[...] o método facilita para os alunos e para o professor, pois, com o método, não temos interrupções e se não entendeu você pode voltar o áudio e escutar de novo. Conteúdos de 1 hora são trabalhados em 20 minutos". Percebe-se, nessa colocação, que, além da melhoria propiciada aos discentes e docentes, ter acesso ao conteúdo previamente também viabiliza otimização do tempo de aula e personalização do tempo de aprendizagem de acordo com o ritmo de cada discente.

Quando os discentes foram inquiridos sobre se acreditavam que esse método torna as aulas mais interessantes e participativas (Gráfico 4), 
constatou-se uma variação maior de respostas, em especial entre as afirmativas e as que representam dúvida.

Gráfico 4-Você acredita que esse método torna as aulas mais interessantes e participativas?

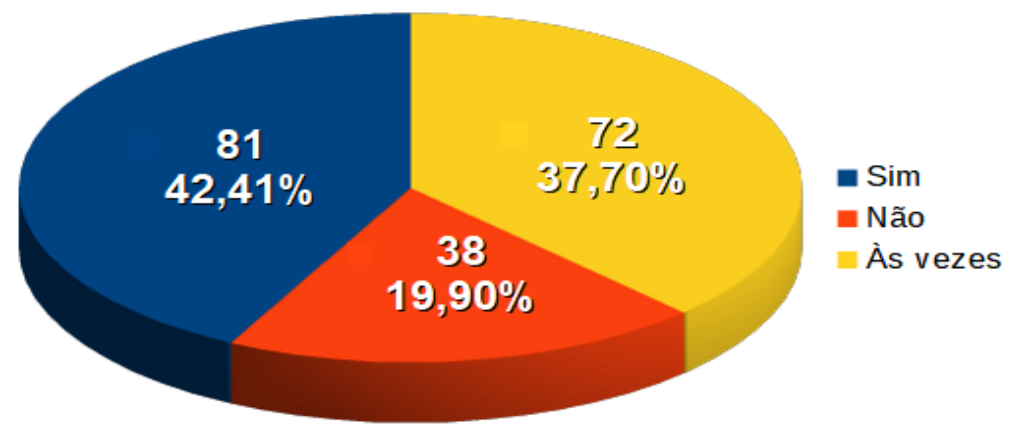

Fonte: Pesquisa realizada pelos autores.

O interesse e a participação dependem muito dos encaminhamentos realizados, da tipologia de material a ser acessado pelos discentes e, principalmente, da disponibilidade de tempo. Em um dos comentários apresentados na questão aberta, um discente do curso de Agroecologia salientou: "[...] por já ter estudado o conteúdo previamente, já sabemos as dúvidas antecipadamente e assim sobra tempo de aula para trazer os assuntos para o nosso cotidiano. Acho um método que facilita e torna as aulas mais interessantes e participativas". Isso é algo de extrema relevância para este estudo, pois aulas interessantes e participativas motivam os discentes e, conforme destacou o Docente A, na resposta da quarta pergunta do questionário docente, "[...] alunos motivados são menos suscetíveis à evasão".

Alguns comentários registrados pelos discentes apontam para algumas dificuldades quanto à utilização do método, por exemplo, no caso dos discentes que trabalham, para os quais é difícil ter tempo de ouvir os áudios e fazer os relatórios (Discente E). Outra observação elencada foi a de que vídeos ou pesquisas livres na internet sobre a temática seriam mais interessantes que ouvir áudios (Discente I). A substituição dos rela- 
tórios por questionários também foi citada como uma forma de melhorar a compreensão e a assimilação dos conteúdos (Discente I). Outro aspecto mencionado foi sobre o tempo dos áudios. De acordo com os discentes, áudios com mais 30 minutos acabam se tornando maçantes, dificultando a compreensão (Discente $\mathrm{E}$ ).

\section{CONSIDERAÇÕES FINAIS}

O uso de tecnologias eletrônicas no cotidiano dos discentes é muito frequente, não só no ambiente escolar, como também nos mais variados espaços e contextos. A internet possibilita uma conexão e interação cada vez maior entre adolescentes e jovens, tornando-se algo indissociável do contexto atual.

Com todo aparato tecnológico disponível para uso no ensino e tendo em vista a necessária e inevitável mudança no modelo de ensino predominante nas escolas, é preciso pensar métodos que se aproximem da realidade dos discentes, despertando-Ihes interesse e motivação, uma vez que, de acordo com dados apresentados neste estudo, uma das principais causas da evasão escolar é a falta de interesse por parte dos discentes.

Dentro desse contexto, a pesquisa realizada possibilita visualizar que tanto docentes quanto discentes veem, no método da Sala de Aula Invertida, uma possibilidade de tornar o processo formativo mais ativo, apresentando contribuições para a aprendizagem e desafios aos docentes para concretizar a sua implantação. Por outro lado, também se observa que esse método não deve ser o único e exclusivo a ser utilizado durante o ano letivo, evitando com que se torne corriqueiro e desinteressante aos discentes.

De acordo com as respostas dos docentes, a Sala de Aula Invertida é uma proposta que favorece também os meios de avaliação, tornando esse processo mais eficiente, pois, nas respectivas aulas, é possível o docente detectar mais pontualmente as dificuldades e as potencialidades apresentadas pelos discentes, podendo, assim, trabalhar diretamente com essas dificuldades. Isso diminui o baixo rendimento escolar e motiva os discentes, impactando positivamente na diminuição dos casos de evasão por fracasso escolar - embora outros fatores também interfiram nessa realidade. 
No âmbito das dificuldades, a pesquisa apresentou aspectos relevantes, como a necessidade do uso da internet para a aplicação do método, algo a que nem todos os discentes têm acesso e, muitas vezes, nem as próprias instituições de ensino possuem internet de qualidade. Outro aspecto é a frequente falta de autonomia dos discentes em programar uma rotina de estudos fora da sala de aula. Mais um aspecto é o de que os discentes, se não forem instigados pelos docentes, dificilmente tomam a iniciativa de estudar algo que não esteja previsto no currículo - e, com raras exceções, não se disponibilizam a fazer algo a mais nas condições de infraestrutura e recursos em que se encontram. Todas essas questões merecem atenção e revelam algumas fragilidades a serem sanadas na implementação do método de maneira mais ampla.

Apesar de ser difícil avaliar o impacto do método na redução da evasão escolar em apenas seis meses de prática, a pesquisa possibilitou verificar o aumento do interesse e da motivação dos discentes com a Sala de Aula Invertida, possibilitando afirmar que esse é um método que se aproxima da realidade dos discentes e da sociedade tecnológica.

Há diversas formas de se concretizar a aula invertida, porém, para se fazer uma escolha assertiva nas técnicas, deve-se avaliar o contexto, isto é, as possibilidades da instituição de ensino, dos docentes e dos discentes. É claro que os resultados obtidos não serão os mesmos em todos os contextos, entretanto é preciso superar as adversidades encontradas, sempre buscando melhorias por meio de constantes avaliações.

\section{REFERÊNCIAS}

BRASIL. Portaria Interministerial n. 10, de 28 de dezembro de 2017. DOU - Diário Oficial da União, 29/12/2017, ed. 249, seção 1, p. 14. Disponível em: http://www. imprensanacional.gov.br/materia/-/asset_publisher/Kujrw0TZC2Mb/content/ id/1498280/do1-2017-12-29-portaria-interministerial-n-10-de-28-de-dezembrode-2017-1498276. Acesso em: 30 jun. 2018.

CAMARGO, Nilce Modesto de; RODRIGUES JUNIOR, Emílio. Uma experiência em ação: aprofundando conceito e inovando a prática pedagógica através do ensino híbrido. In: SIMPÓSIO INTERNACIONAL DE EDUCAÇÃO A DISTÂNCIA. ENCONTRO DE PESQUISADORES EM EDUCAÇÃO A DISTÂNCIA, 2016, São Carlos, SP. Anais [...]. São 
Carlos, SP: UFSCar, 2016, Disponível em: http://www.sied-enped2016.ead.ufscar. br/ojs/index.php/2016/article/view/1295/547. Acesso: 28 jun. 2018.

CAMILLO, Cíntia Moralles. Blended learning: uma proposta para o ensino híbrido. Revista EaD \& Tecnologias Digitais na Educação, Dourados, MS, v. 5, n. 7, p. 6474, 2017.

COSTA, Iraci Cunha Ferreira. A heterogeneidade em sala de aula. Portal Educação. Publicado em 12/12/2013. Disponível em: https://www.portaleducacao.com.br/ conteudo/artigos/pedagogia/a-heterogeneidade-em-sala-de-/52946. Acesso em: 11 set. 2018.

FREIRE, Paulo. Pedagogia do oprimido. 17. ed. Rio de Janeiro: Paz e Terra, 1987.

FRITZ, Mike. How one school turned homework on its head with 'flipped' instruction. PBSNews Hour, 5 dez. 2013. Disponível em: https://www.pbs.org/ newshour/education/what-does-a-flipped-classroom-look-like-2. Acesso em: 30 maio 2018.

GENNERA BLOG. Conheça os 4 benefícios de se aplicar ensino híbrido: sala de aula invertida. Publicado em 26 de setembro de 2017. Disponível em: http://www. gennera.com.br/blog/conheca-os-4-beneficios-de-se-aplicar-ensino-hibrido-salade-aula-invertida/. Acesso em: 31 maio 2018.

INSTITUTO BRASILEIRO DE GEOGRAFIA E ESTATÍSTICA (IBGE). PNAD Contínua 2016. Publicado em 21 de dezembro de 2017. Disponível em: https://agenciadenoticias. ibge.gov.br/agencia-sala-de-imprensa/2013-agencia-de-noticias/releases/18992pnad-continua-2016-51-da-populacao-com-25-anos-ou-mais-do-brasil-possuiamapenas-o-ensino-fundamental-completo. Acesso em: 24 maio 2018.

INSTITUTO BRASILEIRO DE GEOGRAFIA E ESTATÍSTICA (IBGE). Síntese de indicadores sociais: uma análise das condições de vida da população brasileira. 2016. Disponível em: https://biblioteca.ibge.gov.br/visualizacao/livros/liv98965.pdf. Acesso em: 4 ago. 2018.

INSTITUTO NACIONAL DE ESTUDOS E PESQUISAS EDUCACIONAIS ANÍSIO TEIXEIRA (INEP). Inep divulga dados inéditos sobre fluxo escolar na educação básica. Publicado em 20 de junho de 2017. Disponível em: http://portal.inep.gov.br/ artigo/-/asset_publisher/B4AQV9zFY7Bv/content/inep-divulga-dados-ineditossobre-fluxo-escolar-na-educacao-basica/21206. Acesso em: 11 nov. 2018. 
INFOGEEKIE. Evasão escolar: as principais causas e como evitar. Publicado em 23 de abril de 2015. Disponível em: http://info.geekie.com.br/evasao-escolar-asprincipais-causas-e-como-evitar/. Acesso em: 10 set. 2018.

JOHANN, Cristiane Cabral. Evasão escolar no Instituto Federal Sul-Rio-Grandense: um estudo de caso no Campus Passo Fundo. 2012. Dissertação (Mestrado em Educação) - Universidade de Passo Fundo, Passo Fundo, RS, 2012.

LEDESMA, Fernanda. A metodologia blended-learning como mais uma alternativa na formação contínua de professores. Profforma - Revista on-line do Centro de Formação de Professores do Nordeste Alentejano, v. 4, out. 2011.

NERI, Marcelo Côrtes (Coord.). O tempo de permanência na escola e as motivações dos sem-escola. Rio de Janeiro: FGV/IBRE, 2009. (Motivos da evasão escolar). Disponível em: https://www.cps.fgv.br/ibrecps/rede/finais/Etapa3Pesq_MotivacoesEscolares_sumario_principal_anexo-Andre_FIM.pdf. Acesso em: 11 fev. 2020.

SCHNEIDER, Elton Ivan; SUHR, Inge Renate F.; ROLON, Vanessa E. K.; ALMEIDA, Cláudia Mara de. Sala de aula invertida em EAD: uma proposta de blended learning. Revista Intersaberes, v. 8, n. 16, p. 68-81, jul./dez. 2013.

SETÚBAL, Maria Alice. Equidade e desempenho escolar: é possível alcançar uma educação de qualidade para todos? Revista Brasileira de Estudos Pedagógicos, Brasília, v. 91, n. 228, p. 345-66, maio/ago. 2010. Disponível em: http://emaberto. inep.gov.br/index.php/rbep/article/view/577/0. Acesso em: 26 maio 2018.

VALENTE, José Armando. Blended learning e as mudanças no ensino superior: a proposta da sala de aula invertida. Educar em Revista, Curitiba, edição especial n. 4, p. 79-97, 2014.

VILLAS-BÔAS, Marcos de Aguiar. Modelo empregado em Harvard, British Columbia e outras universidades de ponta há alguns anos é muito mais eficiente e inclusivo do que o tradicional. Carta Capital. Publicado em 25 de agosto de 2017. Disponível em: https://www.cartacapital.com.br/blogs/vanguardas-do-conhecimento/aulasinvertidas-sao-muito-mais-eficientes. Acesso em: 1ํo jun. 2018. 